\title{
Pengembangan Perangkat Pembelajaran Matematika Berbasis RME di Sekolah Dasar
}

\author{
Kurnia Puspita Sari, Yerizon, Yanti Fitria, Desyandri \\ (C) 2021 JEMS (Jurnal Edukasi Matematika dan Sains) \\ This is an open access article under the CC-BY-SA license \\ (https://creativecommons.org/licenses/by-sa/4.0/) ISSN 2337-9049 (print), ISSN 2502-4671 (online)
}

\begin{abstract}
Abstrak:
Tujuan dari penelitian yaitu untuk menguraikan perangkat pembelajaran matematika berbasis RME dalam peningkatan kemampuan pemahaman konsep matematis peserta didik yang valid, praktis dan efektif. Penelitian dilaksanakan di SDN 41 Kinali Kabupaten Pasaman Barat. Siswa kelas IV dijadikan subjek penelitian berjumlah 27 orang. Jenis penelitiannya adalah pengembangan dengan model Plomp. Tingkat kevalidan dari aspek isi, bahasa, penyajian oleh validator yaitu 90,09\% dengan kategori sangat valid. Praktikalitas perangkat pembelajaran dari respon guru yaitu $97,3 \%$ dan respon peserta didik sebesar $85,53 \%$ yang diartikan sangat praktis. Kemudian rata-rata hasil tes akhir siswa yaitu 90,83. Maka dari itu diketahui bahwa perangkat pembelajaran matematika berbasis RME yang dikembangkan cocok digunakan di kelas IV SD.
\end{abstract}

Kata Kunci: Perangkat pembelajaran, RME, pemahaman konsep.

\begin{abstract}
:
This study aims to describe a valid, practical and effective RME-based mathematics learning tool for increasing the ability to understand mathematical concepts of elementary school students. The research was conducted at SDN 41 Kinali, West Pasaman Regency. There were 27 grade students in grade IV as research subjects. This type of research is the development with the Plomp model. The validity level of the aspects of content, language, presentation by the validator is $90.09 \%$ with a very valid category. The practicality of the learning tools from the teacher's response was $97.3 \%$ and the response of students was $85.53 \%$ which means very practical. Then the average final test results of the students were 90.83 . Thus it is known that the developed RME-based mathematics learning tool is suitable for use in grade IV SD.
\end{abstract}

Keywords: Learning tools, RME, understanding concepts.

\section{Pendahuluan}

Sejatinya pendidikan merupakan poin utama bagi bangsa justru sebagai komponen penting untuk mengembangkan potensi anak agar menghasilkan sumber daya manusia yang berkualitas. Melalui pendidikan potensi manusia dapat dilatih dan dikembangkan (Ningrum, 2016). Salah satu ilmu pengetahuan yang berkontribusi penuh dalam pendidikan adalah matematika. Menurut Komariyah et al (2018) matematika memiliki lima komponen yaitu bermain bebas, generaliisasi, repesentasi, simbolisaasi dan formalisasii. Diketahui bahwasanya mata pelajaran matematika kuat hubungannya pada pemhaman matematis yang optimal karena dengan hal tersebut siswa mampu menyelesaikan masalah dan dapat merealisasikannnya dalam kehidupan sehari-hari. Maka dari itu diperlukannya pembelajar-

Kurnia Puspita Sari, Universitas Negeri Padang

kurniapuspitasari248@gmail.com

Yerizon, Universitas Negeri Padang yerizonunp@gmail.com

Yanti Fitria, Universitas Negeri Padang yanti_fitria@fip.unp.ac.id

Desyandri, Universitas Negeri Padang

desyandri@fip.unp.ac.id4 
an yang mendorong siswa untuk belajara menemukan konsep dari cara atau pemikirannnya sendiri agar ia memahami konsep tersebut dan dapat mengaplikasikan konsep yang ia pahami dalam kehidupan nyatanya. Matematika ialah ilmu objek abstrak dan tentukan prioritas penalaran deduktif, objek mental abstrak yang tidak dapat diamati dengan panca indera saja (Prananda et al., 2021). Pembelajaran di sekolah harusnya memberikan kesempatan kepada siswa untuk mengembangkan potensinya (Nesusin et al, 2014).

Suksesnya suatu pembelajran juga didukung oleh adanya perangkat pembelajran. Berdasarkan hasil pengamatan pembelajaran yang dilakukan di SD N 41 Kinali diperoleh informasi bahwa guru dalam pembelajaran matematika langsung memberikan rumus/bentuk umum suatu konsep matematika lalu memberikan contoh soal kepada peserta didik dilanjutkan dengan memberikan latihan. Kecenderungan guru mengajarkan materi seperti yang tertera pada buku. Berdasarkan hal tersebut pembelajaran kurang interaktif karena peserta didik tidak terlibat langsung dalam pembelajran. Seharusnya peserta didik ikut andil dalam pembelajaran karena mereka adalah subjek dari pembelajaran (Desyandri, Yohanda, 2020).

Pembelajaran yang seperti itu membuat siswa mengalami persoalan untuk memahami materi dalam matematika (Dogan-Dunlap, 2010). Untuk memecahkan persoalan tersebut guru perlu membuat RPP dan LKPD yang memudahkan peserta didik untuk menemukan sendiri konsep matematika dimulai dengan hal yang dekta dengan kehidupannya. Sungguh sangat disayangkan bahwa RPP dan LKPD yang digunakan di sekolah selama ini belum sepenuhnya mampu memenuhi kebutuhan peserta didik. Padalah, RPP adalah perangkat yang dapat membantu guru dalam mengelola tahapan-tahapan yang akan dilakukan di kelas dan LKPD dapat meringakan guru serta siswa dalam pembelajaran di sekolah. Dengan adanya LKPD dimungkinkan pemahaman konsep peserta didik dapat meningkat, karena di dalam LKPD di muat latihan yang akan menuntun peserta didik untuk melatih kemampuan pemahaman konsep. Jadi, RPP dan LKPD merupakan dua hal sangat memfasilitasi guru serta siswa dalam melaksanakan pembelajaran.

LKPD adalah contoh dari sumber ajar yang memfasilitasi siswa dalam aktivitas penemuan konsep. LKPD merupakan lembar kegiatan proses pembelajaran untuk menemukan konsep baik itu melalui teori, demonstrasi, maupun penyelidikan yang disertai dengan petunjuk dan prosedur kerja yang jelas untuk melatih keterampilan berpikir dan keterampilan proses (Firdaus \& Wilujeng, 2018). Untuk mendukung hal tersebut diperlukan suatu pendekatan pembelajaran sebagai acuan dalam mengembangkan RPP serta LKPD. Salah satu alternatif pendekatan yang digunakan adalah Reaalistic Mathematics Education (RME). Menurut Jarmita \& Hazami (2013), pendidikan matematika realistik adalah pendekatan dicirikan kepada hal-hal konkret menurut peserta didik, mengutamakan keterampilan melakukan proses maematika, berdiskusi dan bertukar ide dengan teman sekelas dengan demikian mereka menemukan sendiri konsep tersebut, sehingga mereka dapat memecahkan masalah dan dan dapat menerapkan konsep yang ia pahami dalam kehidupan sehari-hari. Selanjutnya menurut Claudia et al., (2020) Realistic mathematics education is a learning approach based on the use of mathematical problems taken from real experiences to represent abstract concepts from mathematics. Bersumber pada hal tersebut, dikarenakan pentingnya pengoptimalan kemampuan konsep, prosedur dan sifat pada pembelajaran matematika, maka perlu kiranya jalan keluar untuk menanggulangi persoalan di atas dengan cara membuat suatu perankat pemblajaran yang dapat mengaktifkan peserta didik dalam kegiatan belajar di sekolah. Perngkat pemblajaran yang dirancang adalaha Lembar Kerja Peserta Didiik (LKPD) dan Rencana Pelaksanaan Pembelajarn (RPP) menggunakan pendekatan matematika realistik. 


\section{Metode Penelitian}

Penelitian ini dikategorikan penelitian pengembangan karena dilaksanakan dengan prosedur ilmiah dalam merancang suatu produk (Suandi, 2016). Dengan model Plomp, ada 3 tahapan yaitu penelitan pendahuluuan meliputi analisis kebuutuhan, analisiis kurikulum, dan analisis konsep. Tahapan kedua pengembangan adalah proses merancang serta mengembangkan LKPD dan RPP secara bertingkat memakai evaluasi formatif difungsikan untuk menyempurnakan produk yang dibuat. Tahapan terakhir yaitu penilaian semi sumaatif untuk merumuskan apakah LKPD dan RPP sesuai berdasarkan aturan baku penelitian. Peserta didik kelas IV SDN 41 Kinali dilibatkan sebagai subjek penelitian ini.

Data dalam penelitian ini menggunakan data kualiitatif serta kuntitatif. Data kualitatif didapatkan dari lembar pengamatan, hasil wawancara sedangkan data yang sifatnya kuantitatif didapatkan melalui hasil angket, lembar validasi, lembar pengamatan keterlaksanaan RPP berbasis RME. Teknik analisis datanya yaitu deskriptif kualitatif serta kuantitatif. Deskriptif kuantitatif berkaitan dengan kevalidan produk yang dibuat serta kualitatif bertujuan untuk menjelaskan produk yang dibuat.

\section{Hasil dan Pembahasan}

Riset dimulai dengan tahapan penelitan pendhuluan yaitu analisiis kebutuhan,kuriikulum, pesert didk dan konseptual. Hasil analisisnya adalah sebagai berikut: Tahap analisis kebutuhan, mengumpulkan informasi tentang pembelajaran matematika beserta alasannya, pelaksanaan pembelajaran dan penggunaan perangkat pembelajaran. Hasil observasi didapatkan beberapa informasi bahwa kegiatan beljar mengjar berorientasi kepada guru peserta didik belum terbiasa mengkonstruksi pengetahuannya sendiri. Proses pembelajaran tidak membantu siswa menemukan konsep matematika, siswa hanya belajar mengidentifikasi rumus dan menggunakannya untuk memecahkan persoalan. Kemudian analisiis kuriklum, dilaksanakan telaah Kurikulum 2013 untuk pelajaran matematika kelas IV pada semester II. Analisis berupa rumusan indikator pencapaian kompetensi (IPK) yang ada pada silabus. Penjabaran KI, KD dan IPK menjadi alasan untuk memilih materi. Analisis pserta didk diketahui siswa lebih senang belajar dengan sumber belajar yang memiliki kombinasi gambar dan warna. Dalam kegiatan pembelajaran peserta didik sering merasa jenuh karena guru terlalu lama menerangkan pembelajaran maka dari itu diperlukan sumber belajar yang membuat mereka termotivasi untuk belajar. Kemudian setelah dilakukan analisis konsep didapatkan 6 konsep utama yang akan dirancang yaitu 1) keliiling persegi, 2) luss persegi, 3) keliling perseegi panjang, 4) luas prsegi panjang, 5) kelilig segitiga, 6) luas segiitiga. Informasi tersebut dijadikan pertimbangan dalam membuat perangkat pembelajaran yaitu RPP dan LKPD berbasis RME.

Berdasarkan hasil analisis validitas RPP untuk setiap aspek pada RPP dikategorikan sangat valid dengan nilai validitas 92,91\%. Dikatakan bahwa RPP berbasis RME ini telah valid. Hasil validasi RPP dapat diliihat pada tabel 1:

Tabel 1. Nilai Validitas RPP

\begin{tabular}{llll}
\hline No & Cakupan & Nilai Validitas & Kriteria \\
\hline 1 & Identitas Mata Pelajaraan & $100 \%$ & Sangat Valid \\
2 & Kompetensi Dasarr & $100 \%$ & Sangat Valid \\
3 & Perumusan Indikator & $95 \%$ & Sangat Valid \\
& Pembelajaran & & \\
4 & Perumusan Tujan Pembelajaran & $90 \%$ & Sangat Valid \\
5 & Pemilihan materii pembelajaran & $88,33 \%$ & Sangat Valid \\
\hline
\end{tabular}




\begin{tabular}{llll}
\hline 6 & Pemilihan strategi pembelajaraan & $92,50 \%$ & Sangat Valid \\
7 & Pemilihan Sumber Belajar & $90 \%$ & Sangat Valid \\
8 & Pemiliihan Media Pembelajaran & $90 \%$ & Sangat Valid \\
9 & Langkah-langkah Kegiatan & $93,75 \%$ & Sangat Valid \\
& Pembelajaan & & \\
10 & Penilaian & $90 \%$ & Sangat Valid \\
11 & Bhasa dan penulisan & $92,50 \%$ & Sangat Valid \\
Rata-rata Keseluruhan & $92,91 \%$ & Sangat Valid \\
\hline
\end{tabular}

Kemudian setelah dilakukan validasi LKPD diperoleh hasil validasi LKPD secara keseluruhan yaitu 90,09\% yang diartikan sangat valid. Disimpulkan bahwa LKPD berbasis RME telah valid. Hasil validasi dapat dilihat di bawah ini:

Tabel 2 Nilai Valiidasi LKPD secara Keseluruhan

\begin{tabular}{llcc}
\hline No & Cakupan & $\begin{array}{c}\text { Nilai } \\
\text { Validitas }\end{array}$ & Kriteria \\
\hline 1. & Penyajian dan kelayakan isi & $92,91 \%$ & Sangat valid \\
2. & Bahasa & $91,67 \%$ & Sangat valid \\
3. & Kegrafikan atau tampilan & $85,71 \%$ & Sangat Valid \\
\multicolumn{2}{c}{ Rata-rta } & $90,09 \%$ & Sangat Valid \\
\hline
\end{tabular}

Bersumber pada tabel tersebut, segi validitas isi dan konstruk untuk RPP sudah valid. Maka RPP dapat dipakai guru untuk melaksanakan pembelajaran berbasis RME. Kemudian analisis validitas LKPD secara umum yaitu 90,09\% yang diartikn sangat valid. Hal itu membuktikan bahwa LKPD yang dibuat sudah mencakup kriteria valid. Nilai uji praktikalitas LKPD respon peserta didik dapat dilhat di bawah ini:

Tabel 3. Angket Tanggapan Peseerta Ddik

\begin{tabular}{llccc}
\hline No. & \multicolumn{1}{c}{ Aspek } & Rata-rata & Persentase & Kriteria \\
\hline 1. & Penyajian & 3,49 & $87,25 \%$ & $\begin{array}{l}\text { Sangat } \\
\text { Praktis }\end{array}$ \\
2. & Penggunaan & 3,41 & $85,25 \%$ & $\begin{array}{l}\text { Sangat } \\
\text { Praktis }\end{array}$ \\
3. $\quad$ Keterbacaan & 3,28 & $82,12 \%$ & $\begin{array}{l}\text { Praktis } \\
\text { 4. } \quad \text { Waktu }\end{array}$ \\
Rata-rata Kepraktisan & 3,50 & $87,50 \%$ & $\begin{array}{l}\text { Sangat } \\
\text { Praktis }\end{array}$ \\
& & $\mathbf{3 , 4 2}$ & $\mathbf{8 5 , 5 3 \%}$ & $\begin{array}{l}\text { Sangat } \\
\text { Praktis }\end{array}$ \\
\hline
\end{tabular}

Berdasarkan pemaparan tersebut, terlihat bahwa hasil kepraktiisan LKPD berbasis RME dari respon siswa yaitu $85,53 \%$. Dapat dikatakan bahwasanya LKPD berbasis RME sangat praktis bagi siswa. Untuk mengetahui praktikalitas RPP dan LKPD dengan guru kelas IV B SDN 41 Kinali dilakukan setelah pembelajaran dilaksanakan.Angket praktikalitas perangkat pembelajaran berbasis RME menurut respon guru terlihat seperti berikut:

Tabel 4. Hasil Angket Respon Guru

\begin{tabular}{clccc}
\hline No. & Aspek & Rata-rata & Persentase & Kriteria \\
\hline 1. & Penyajian & 3,75 & $93,75 \%$ & Sangat Praktis \\
2. & Penggunaan & 3,81 & $95,45 \%$ & Sangat Praktis \\
3. & Keterbacaan & 4 & $100 \%$ & Sangat Praktis \\
4. & Waktu & 4 & $100 \%$ & Sangat Praktis \\
& Rata-rata Kepraktisan & $\mathbf{3 , 8 9}$ & $\mathbf{9 7 , 3 \%}$ & Sangat Praktis \\
\hline
\end{tabular}


Berdasarkan penjelasan tersebut, terlihat persentase tingkat kepraktisan perangkat pembelajaran berbasis RME menurut respon guru adalah 97,3\%. Dijelaskan bahwasanya perangkat pembelajaran berbasis RME sangat praktis dari aspek guru. Kemudian efektiviitas perangkat pembelajaran matematiika dilihat dari nilai tes akhir. Ujian akhir diberikan kepada siwa selesai proses pembelajaran dengan memakai LKPD serta RPP RME dengan 5 buah soal uraian. Persentase ketuntasan hasil belajar dapat dilihat dibawah ini:

Tabel 6. Persentase Tes Akhir

\begin{tabular}{llll}
\hline \multirow{2}{*}{ Tes Akhir } & \multicolumn{3}{c}{ Ketuntasan } \\
& Tuntas & Tidak Tuntas & Total \\
\hline $\begin{array}{l}\text { Jumlah Peserta } \\
\text { Didik }\end{array}$ & 10 & 2 & 12 \\
\hline Persentase & $84,85 \%$ & $15,15 \%$ & $100 \%$ \\
\hline
\end{tabular}

Pada Tabel 6 terlihat ada 10 orang dari 12 orang peserta didik yang tuntas. Hal ini mengindikasikan bahwa siswa yang tuntas yaitu $83,33 \%$ dan yang belum tuntas $16,67 \%$. Rata-rata tes akhir peserta didik adalah 90,83. Berdasarkan kriteria hasil belajar pada tabel 6, maka perangkaat pembelajaran matematiika berbasis RME sudah efektf.

\section{Kesimpulan}

Riset ini mewujudkan sumber belajar berupa RPP serta LKPD yang valid, praktis dan efektif melalui model Ploomp. Tahapannya yaitu tahap peneltian pendahuluan, pengembangan dan penilaian. Tahap pertama tersebut dilakukan analisiis kebtuhan, kurkulum, peseta didik dan materi sebagai awal untuk membuat perangkat. Tahap kedua dilaksanakan penilaian formatif mulai dari penilaian sendiri, validasi ahli, penilaian perorangan, kelompok kecil dan uji lapangan sehingga didapatkanlah perangkat yang valid dan praktis sehingga cocok digunakan di sekolah. Tahap ketiga dilaksanakan tes kemampuan konsep kepada siswa tujuannya untuk melihat dampak dari sumber belajar yang telah diberikan. Dari segi isi perangkat yang telah dibuat dikategorikan sudah sahih. Dilihat hasil lembar respon guru dan pesert didik perangkat yang dikembangkan termasuk kriteria praktis. Kemudian perangkat yang dikembangkan dalam kriteria praktis hal tersebut dibuktikan dengan rata-rata tes akhir siswa yaitu 90,83 yang berdasarkan pada kriteria hasil belajar yaitu baik sekali.

\section{Daftar Rujukan}

Claudia, S., Suryana, Y., \& Pranata, O. H. (2020). Pengaruh Pendekatan Matematika Realistik terhadap Hasil Belajar Siswa Kelas II Pada Perkalian Bilangan Cacah di Sekolah Dasar. PEDADIDAKTIKA: Jurnal Ilmiah Pendidikan Guru Sekolah Dasar, 7(2), 210-221.

Desyandri, Yohanda, R. (2020). Peningkatan Hasil Belajar Tematik Terpadu Siswa dengan Menggunakan Model Saintific di kelas III SD Negeri 01 Koto Tangah Simalanggang. 3(2).

Dogan-Dunlap, H. (2010). Linear Algebra Students' Modes of Reasoning: Geometric Representations. Linear Algebra and Its Applications, 432, 2141-2159.

Firdaus, M., \& Wilujeng, I. (2018). Pengembangan LKPD inkuiri terbimbing untuk meningkatkan keterampilan berpikir kritis dan hasil belajar peserta didik Developing students worksheet on guided inquiry to improve critical thinking skills and learning outcomes of students. Jurnal Inovasi Pendidikan IPA, 4(1), 26-40. http://journal.uny.ac.id/index.php/jipi 
Jarmita, N., \& Hazami, H. (2013). Ketuntasan Hasil Belajar Siswa Melalui Pendekatan Realistic Mathematics Education (Rme) Pada Materi Perkalian. Jurnal Ilmiah Didaktika, 13(2), 212-222. https://doi.org/10.22373/jid.v13i2.474

Komariyah, S., Afifah, D. S. N., \& Resbiantoro, G. (2018). Analisis Pemahaman Konsep Dalam Memecahkan Masalah Matematika Ditinjau Dari Minat Belajar Siswa. SOSIOHUMANIORA: Jurnal Ilmiah Ilmu Sosial Dan Humaniora, 4(1), 1-8. https://doi.org/10.30738/sosio.v4i1.1477

Nesusin, N., Intrarakhamhaeng, P., Supadol, P., Piengkes, N., \& Poonpipathana, S. (2014). Development of Lesson Plans by the Lesson Study Approach for the 6th Grade Students in Social Study Subject Based on Open Approach Innovation. Procedia - Social and Behavioral Sciences.

Ningrum, E. (2016). Pengembangan Sumber Daya Manusia Bidang Pendidikan. Jurnal Geografi Gea, 9(1).

Prananda, G., Friska, S. Y., \& Susilawati, W. O. (2021). Pengaruh Media Konkret Terhadap Hasil Belajar Materi Operasi Hitung Campuran Bilangan Bulat Siswa Kelas IV Sekolah Dasar. JEMS: Jurnal Edukasi Matematika Dan Sains, 9(1), 1-10. https://doi.org/10.25273/jems.v9i1.8421

Suandi, D. (2016). Pedoman Penulisan Karya Ilmiah. Universitas Pendidikan Ganesha. 